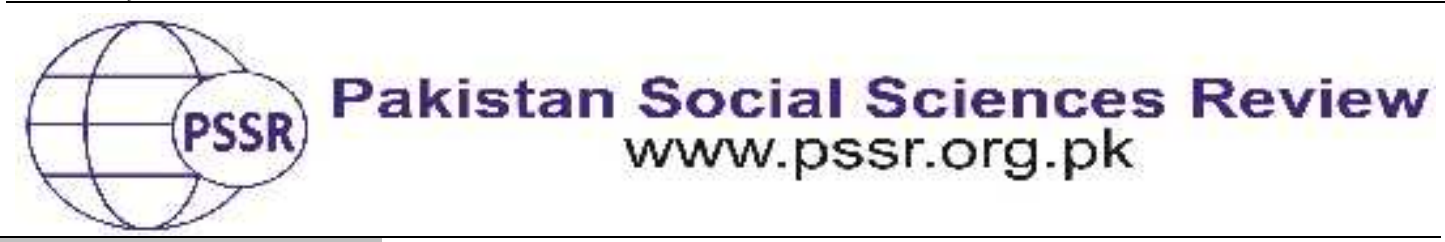

RESEARCH PAPER

\title{
Ecofeminist Paradigm and South Asian Fiction: An Analysis
}

\author{
Nargis Saleem* ${ }^{*}$ Dr Muhammad Saleem ${ }^{2}$ Umer Azim $^{3}$
}

1. Lecturer, Department of English, Riphah International University, Lahore, Punjab, Pakistan

2. Professor, Department of English, Govt. College Township, Lahore, Punjab, Pakistan

3. Assistant Professor, Department of English, Government College Township, Lahore, Punjab, Pakistan

\begin{tabular}{|c|c|}
\hline $\mathbf{P A}$ & \\
\hline & \multirow{9}{*}{$\begin{array}{l}\text { This study pursues the analysis of chosen fiction of Khaled } \\
\text { Hosseini and Amitav in the light of ecofeminism. The crux of } \\
\text { ecofeminism expands on analogies between woman and nature, } \\
\text { on the one hand, and the male and culture, on the other hand. } \\
\text { Male generally naturalizes woman as a culture feminizes nature. } \\
\text { With the space of technological development, the exploitation of } \\
\text { nature has increased exceedingly as the male have been } \\
\text { exploiting the female since centuries. Both male and culture } \\
\text { discursively produce their second part of binaries that is female } \\
\text { and nature to define themselves as the creator. In the pursuit of } \\
\text { ecofeminist investigation various types of exploitation of nature } \\
\text { and marginalization of a woman are traced. There are numerous } \\
\text { significant results of this exploitation; the implications of the } \\
\text { coercion are very deep rooted and work on various levels of life. } \\
\text { As a result of this phenomenon, the female characters of these } \\
\text { novels do intentionally take various measures to preserve } \\
\text { nature. It is a significant study to acquaint the reader with the } \\
\text { widespread environmental degradation and female oppression } \\
\text { in South Asia }\end{array}$} \\
\hline & \\
\hline & \\
\hline & \\
\hline & \\
\hline & \\
\hline & \\
\hline & \\
\hline & \\
\hline
\end{tabular}

\section{Introduction}

Radical feminism, cultural feminism and socialist feminism produced so many impacts and influences on the sociopolitical thoughts; ecofeminism is certainly one of them. The term ecofeminism that was coined by Francoise d'Eaubonne got popularity in so many disciplines and one of them is literature. Eaubonne's ecofeminism believes that oppression is everywhere in the world and a close gaze tells us that it is the direct and indirect result of the exploitative character of the patriarchal praxis (1974).She also holds that the widespread patriarchal practices led to the exploitation of natural resources and the degradation of the environment. 
There are multiple benefits that make researchers go for ecofeminism as a theoretical framework for their studies. It broadens the base and scope of feminist theories. It also imparts comprehensiveness to the research that we are going to initiate. There is an exclusive insistence among the researchers on the argument of actual contribution to the society and culture.In this background, ecofeminism is a very promising candidate to the purpose. Both male and the worldly product of humans that is called culture have adopted a political role in today's world. We can use the Derridean idiom of binary to explain the point. Culture practically has adopted the role of first part of Derridean binary which implicationally means that the second part of binary i.e. nature is supposed to absolutely serve but the selfish aims and objectives of the first part. Nature once in the past was free and independent to provide a pleasant background to humans. But now it has been colonized by culture which is a symbol of maleness or patriarchy. On the same lines, the male produce their second part of binary in the form of a female to exploit and fleece her.In this background, we can say easily that culture has feminized nature and the male has naturalized woman. The basic argument of ecofeminism is that patriarchal society's values and beliefs have resulted in the oppression of both women and nature. It ignores women's work, knowledge and 'situatedness'. In the western thought and literature, nature and culture are one of the oldest binaries. Ecofeminists say that both the parts of this binary are gendered: nature is a female metaphor and culture is a male sign. Masculine culture is linked with mind, objective, rational and public. On the other hand, feminine nature is linked with body, subjectivity, emotional and private. Images like 'mother nature' achieve two purposes: they naturalize women and they feminize nature. It means women are linked with reproduction and nurture only. These functions of a female are considered 'natural' to her. Ecofeminism rejects all these formulations calling it a man/male made world.

These above mentioned arguments justify the popularity of ecofeminism among researchers. South Asian literature is with an orientation to this paradigm of ecology and feminism that tempts the present researchers pursue their present research with the help of ecofeminism in the context of selected short fiction of South Asian region.

\section{Literature Review}

There are so many significant pieces of work that were informed by the cultural theory of ecofeminism. Its widespread value is due to its close relevance to gender discrimination and the exploitation of nature occasioned by the overtures of capitalism. Bhalla (2019) in his article Ecofeminism in Margaret Atwood's Surfacing analyzes the role of nature and woman for each other in a very creative way. The unnamed protagonist heroine of the novel Surfacing is caught between two worlds: the world of the male and the world of nature. Her husband wounds her literally, emotionally and psychologically to such an extent that she has to move to the world of nature and forest for relaxation and recuperation. The wood provides everything 
she needs; she finds different objects of nature around that are more inspirational and compassionate to her. This world of nature gives courage to stand against her bullying husband one day. The damage done to nature and the female by man is similar. Scientific advancement and technology symbolize the lust of the male that howls for more and more in terms of land, jungle and woman.

Shiva (1988) in his famous writing Staying alive: Women, ecology and survival in India very significantly traces the history of man that starts from cave and comes to the modern existence of technology. To Shiva, the best life for women was the initial phase where they co-existed with nature and lived a natural life. Colonialism is seen as the worst form of capitalism that provided the western male to grab the land more and more and expand the technology to the alarming extent. Colonial masters with the help of their technology enabled the colonized man to go deeper and deeper in their exploitation of woman and nature. In this colonialism technology was the bitterest curse that poisoned the life of man and woman. Reproductive technologies have strengthened the hands of the male to a dangerous extent because they use both nature and woman just as the absolute owners of them. Shiva believes that it is a must for the modern world to ensure the freedom of woman, nature and the animals so that exploitation one day is far away to let the weaker sections of the society breathe freely.

Usmani (2017) in his research Ecofeminism in Anita Desai's Where shall we Go this Summer explains the evil nexus between the male and industrialization. With the advancement of scientific technology, the value of nature as the companion and solace for man is decreasing and it suits the male a lot. The male commodify it as they commodify a woman. The aesthetic character of both the marginalized is lost. She says that woman often do not do anything to get themselves liberated form the cruel clutches of patriarchy and this is their dilemma. They often are unable to realize their dreams due to the prevalence of patriarchy and are all the time on their toe to enter into the house of their husband as an obedient bride. She believes that only through her reliance on nature, she can one day actualize herself.

Both nature and woman are presented as the world of mysteries in Rao's research A Study of Feminism in the Novel Mistress of Spices (2016). Man in search of his curiosity to know these mysterious world's first praises it and when the mysteries are known, he devalues it repeatedly. Tilo, the central character of the novel, is thrown into two opposite worlds by the author to make the reader see which world is better than the other world. When she is in the lap of nature, she is doing the role of a natural physician to treat every type of disease there in the jungle. Serpents that often stand for the sign of poison, save Tilo from drowning. Nature is at her beck and command. Her internal and external dimensions of life are all enviable but when she decides to leave the forest, the fortune stops smiling on her. Pirates kidnap her and her parents are killed mercilessly.

All these above reviewed pieces of research are significant from different aspects and are often cited by the new researchers in their studies. There are so many significant points of research in these studies that constantly attract the attention of 
researchers. Up till now no one of these valuable researchers has analyzed Ali, Ghosh and Hosseini's fiction from the perspective of ecofeminism. Hence the present piece of research.

\section{Theoretical framework}

The research under process is analytical and qualitative in orientation. The theoretical framework to inform this study is ecofeminism. There are so many models and variations of this literary and cultural theory but for the present research the formulations of Francoise d'Eaubonne, Greta Gaard and Janis Birklandare harnessed. The key terms of the ecofeminist theory used in is research is discussed in brief here. The male are always hungry after land, forest, minerals and women. They have developed 'their' own language in which they discursively ideologize their relationship with the surrounding. They in their discourse try to justify their hegemony on the environment and woman. Ecofeminism accounts for the patriarchal practices that work in the processes of their militarism, violence, oppression against the female and nature. These theorists on ecofeminism also in detail discuss the natural closeness of the female characters with nature. They trace various similarities and dissimilarities among woman and nature. The male appear as the site where the variant processes of capitalism are exerted. Colonialism and technology both work for strengthening the exploitative role of the male against the feminized nature and the naturalized female. Reaction from woman and nature against their vandalizers is usually lukewarm. However, there are growing bond between nature and the oppressed woman is intact. This theory believes that the liberation of woman from the cruel clutches of the male is synchronized with the freedom of nature from the coercive and exploitative strategies like modern developed machinery that exerts huge losses to nature and living creatures living there.

\section{Data Analysis}

In this section of the present research theory of ecofeminism is applied on the two fictional narratives of The Hungry Tide and A thousand Splendid Suns. This analysis is done in the light of the given research questions. All the three research questions are investigated here in the context of these novels. It is the heartiest desire of the male in The Hungry Tide to buy more and more pieces of land and then turn them to paddy fields. The poor are asked to work over these fields and in this way both the poor, the female and land are all exploited by the male (Gaard, 1993, p.1).

Piya who is the protagonist of the novel The Hungry Tideis on her way to Sundarbans for her research on the character of fresh water dolphins when she meets the patriarchal character Kanai on train. When Piya is trying to take a cup of tea from the tea seller, Kanai's elbow gesture makes tea split over her. He does not express any sorry to Piya, rather he remains complacent in his chauvinistic bent of mind. Piya knows very well that it is the fault of Kanai and remains eager to listen the words of sorry from his side. Then addressing Kanai she expresses herself thus: 
"I'm very sorry. I hope you'll excuse me" (Ghosh, 2004, p.18).She faces this situation wherever she moves in the novel. She is very happy to see that she gets permission from the authorities within four hours to go for her research on the river. But soon she feels herself helpless when the controlling authorities send a guard along with Piya to the river. Her helplessness does not stop here, it continues to a long time. The guard who represents the exploitative mechanism of male chauvinism again and again displays through his weapons and gestures that his powers over the area and the people of the are the powers of a god. In the presence of the guard it becomes very difficult for Piya to proceed with her research objectives: "her experience with guard had bruised her confidence" (p.48). Then the guard hands over Piya to Mejda, a local boat man who is the stooge of the controlling authorities. This boatman is a terror to the other poor boatmen, as he destroys the boat if someone tries to take the tourists or researchers on his boat. Mejda exercises brutal power against a poor fisherman and his son when the later ignores the gaze of the former. Piya feels that boat and the people around are all under the authoritative powers who do not allow anyone to have his or her choice of life. She feels herself a hostage there who is unable to have a boatman of her own choice.

In contrast to the brutal male chauvinism all around Piya, the supportive role of nature is contrasted. Piya lived a very boring and dull life in America where her parents were all the time busy in tug of war with each other to insult and degrade each other. This suffocating atmosphere at her home in America symbolizes the failure of cultural to accommodate and facilitate man. But when she leaves America and comes to the subcontinent for her research on the behaviors of dolphins of fresh water, her life is changed. Unlike the culture of America, the world of nature is kind, restorative and benign for Piya. Herself that remained lost in the West is restored to her. Her meaningless existence turns into a creative and dynamic phase of life. All the rust on existence is removed and from beneath there emerges a shine of plastic and mobile life. Her wasteland is transformed into a lush green vista of happiness and the salvation is realized (Saleem, 2015). When she ponders over the crabs, she laughs and continues to be in the enviable positive mood. She hated even the phonology of Bengali language that was spoken at her parents' house in America. But when she is in the Sundarbans, she loves to hear and understand the diction and syntax of this language. All of her prejudice against the said language is gone.

Ecofeminists hold that both nature and woman are oppressed by culture and the male chauvinism. The male generally feels joys in the destruction and devastation of both female and nature. Nature has provided animals, birds and other living beings with the right of independent living and space for this living. But the patriarchal praxis snatches this right forcibly. One day Piya hears a noise coming from the shore there. She wants to go to the source of that noise but Kanai asks her not to go there as it was not safe for her to visit that place. A tiger that had attacked a human there in the jungle was being killed by the male there. Piya asks her boatman Fokir to save the tiger but he remains silent. The research proves that when man tries to snatch the land and habitat of the wild animals, they sometimes react very badly. Like the land of the tiger, the world of Piya is devastated by her ex-lover Rath. She 
was very confident of her lover and his loyalty to her. Once she went away from the town on a special job of a week. Her lover married some other woman and went away from the city. When she comes back, she is shocked to hear the disloyalty of her lover who having ruined the life of one woman now is busy in the destruction of life of another woman. But her world like the world of the tiger is destroyed but she does not react in the way the jungle beast had reacted. This noncommittal behavior of Piya further encourages Rath to go on the series of damages to the woman folk. The woman there "they just laughed" (Ghosh, 2004, p. 705) as it is a common fate of women to be exploited at the hands of the male.

Hosseini's novel Thousand Splendid Suns set in the Afghan region of Afghanistan where greenery and wild life is not as abundant as we see in The Hungry Tide. But even then the exploitation of woman, nature and land is going on uninterrupted. Laila who is one of the two central female characters of the novel under discussion is the site of constant fleecing at the hands of the male folk close to her and an image that bears damages like the harms imparted to the land around her. Her father who always bullied her mother married her to a male who was double of her age. The story of the other female character Maryam is also with the same level of damage done at the hands of the male fellows. The social institutions also play their role effectively to let her be exploited exceedingly (Saleem, 2015). She becomes the victim of all the repressive and ideological institutions. The land, infrastructure and nature in Afghanistan is raped, devastated widely especially at the hands of Talibans who implied the coercive and hegemony on everything there. There are so many parallels drawn by Hosseini between the two oppressed entities: woman and nature. The use of dangerous weapons that puts an end to so many lands, mountains, trees is compared with the various types of oppression concerning woman.

When Maryam lives with her mother away from the presence of her father, she is happy and contented. Both her mother and nature around nourish her healthily and effectively. The land and her mother in fact work as the symbol of mother earth that provide her with all the 'nutrients' to make and keep her rapturous and normal. The writer intentionally creates this idyllic in the life of Maryam: he is going to contrast it with the hard times of long life of Maryam. She used to play with pebbles that healed up all of her bodily and psychic wounds. Then she makes an error of judgment that brings her tragedy to the alarming heights."Ecofeminism describes the framework that authorizes these forms of oppression as patriarchy, an ideology whose fundamental self/other distinction is based on a sense of self that is separate, atomistic" (Gaard, 1993, p. 2). She, without taking permission from her mother, moves to the house of her father; Maryam always remained in search of her 'loving' father. She enters into a different but difficult phase of her life where the motherliness of the mother does not exist. There are series of cruel behaviors that Jalil, the father of Maryam, exercises on his daughter plus wife. First, he falls in love with the young mother of Maryam; when 
she gives birth to an illegitimate daughter, she is thrown out of the boundaries of Herat where the rich Jalil used to live.

When Maryam comes to her father's house to live there, the doors are closed to her. Then her father takes her indoors but the 'loving' father that she always visualized was absent in reality. Verbally he is very kind to her but in practice he is just a fleecer. His sugar coated diction for her daughter is contrasted with his decision to marry Maryam to a man double of her age. She makes resistance to the fatherly decision but in vain; he remains adamant and ultimately she is handed over to an old man as a wife. Her stay with father and her stay with her mother are in a sharp contrast to each other. The traditional ideologies are so powerful that the individual ad a rebel is unable to successfully bang against the existing set of systems (Saleem, 2011). The more the resistance she shows, the more the slavery deepens on her and her existence. Then we see her moving from pillar to post.

There are various events that expose Maryam to the atrocities of patriarchal values that ultimately crush her. Rasheed, the husband of Maryam, is always in a chauvinistic mood after marriage. She displays himself at home as a supreme creature in front of Maryam. This mood of the patriarch is juxtaposed with his mood when Maryam gets pregnant. Like a peacock, he often struts literally and verbally. He sits usually sits in the lawn and spreads his smile along all of his face. Reason is simple. He believes that Maryam is going to produce a male child soon that would amount to her patriarchal mindset. Maryam herself feels this change clearly in the behaviors of Rasheed. He shares his jokes and pleasure based talk with his wife. One day the fate frowns at her and miscarriage occurs. The orientation of Rasheed is transformed dialectically. He now often taunts at her; calls her idiot and uneducated who just like an animal in her behaviors. "It wasn't easy tolerating him talking this way to her, to bear his scorn, his ridicule, his insults, his walking past her like she was nothing but a house cat" (Hosseini, 2007, p. 89). Here both Maryam and land are suggestively compared through the discourse of the novel. If a piece of land does not produce the intended amount/quality and type of crop, the male farmer calls it a wasteland/sinister land/useless patch of soil where only animals are to graze. Same is the case with Maryam, a representative of the South Asian oppressed ladies. When she experiences miscarriage, all of her shine and value is diluted. Now she is to work a laughing stock in the house where her male partner would continue to degrade, dehumanize and depersonalize her till her death.

\section{Conclusion}

The present research demonstrates various forms and levels of exploitation of woman and nature in The Hungry Tide and A thousand Splendid Suns. The body of woman is generally used for different purposes: to satisfy the sexual desire of the male, to produce the children for the male, to receive physical beatings at the hands of the patriarch when he likes to do so; to work as slave in the four walls of the house and to get vibration at the shouts of the life partner. Same is the case with the land, nature and the living organisms there. Nature and land are the geographical colonies of the egoistic and egotistic male. He plants crops on the land by removing 
the natural greenery and natural context. Then disturbs the ecosystem of the area by destroying the natural habitat of the living creatures. The animals are sometimes also killed to establish his smooth hegemony over the land. The hunter of the land and woman is never satisfied with his 'conquests'. He is like the ocean all the time howling for more and more. He tries to exploit both the woman and nature to such an extent in these two novels that their regeneration seems impossible. There are very close resemblances and ties between nature and woman. Women always feel supported by nature, when they are close to it physically and mentally. The only idyllic in the life of women in these two novels is realized properly when they are away from artificial society and are in firm contact with animals, land and the natural environment. Their distance from nature brings them closer to the attacks of the male. Women are also reciprocal in their relation with nature. They support the natural order of nature and that of ecosystem. They always try to preserve the natural beauties and the wildlife as much as possible. There exists some 'unwritten' but lovely bon between nature and woman. On the other hand, culture and the male always complement each other as the partners of crime against nature and woman. 


\section{References}

Ali, A. (1994). Twilight in Delhi. New Directions Paperbook

Bhalla, M. (2019). Ecofeminism in Margaret Atwood's Surfacing. International Journal of Scientific and Publication, 2(10),1-6. doi:10.29322.

Eaubonne, F. (1974). Le Feminiseou la. Paris: P.Horay.

Ghosh, A. (2004). The hungry tide. London: Harper Collins

Hosseini, K. (2007). The Thousand Splendid Suns. London: Bloomsbury Publishing.

Rao, R. (2016). A Study of Feminism in the Novel Mistress of Spices. IOSR, Journal of Humanities and Social Sciences, 21 (11), 46-49.doi:10.9790/0837-2111074649

Saleem, M. (2011). Analysing Tariq Rahman's story The Dance of the Beardsin the light of Barthes' narrative codes. Language in India, 11(11), 647-666.

Saleem, M. \& at el. (2015). The Waste Land by T. S. Eliot: A site for inertia in motion. Gomal University Journal of Research, 31(2), 182- 193.

Saleem, M, At el. (2015). Analysing the Paralysis Phenomenon in Eveline by James Joyce. ELF Annual Research Journal 17(1), 197-208.

Shiva, V. (1988). Staying alive: Women, ecology and survival in India. London: Zed Books.

Usmani, F. (2017). Ecofeminism in Anita Desai's Where shall we Go this Summer. Lapis Lazuli: An International Literary Journal, 7(2), 198-203. 